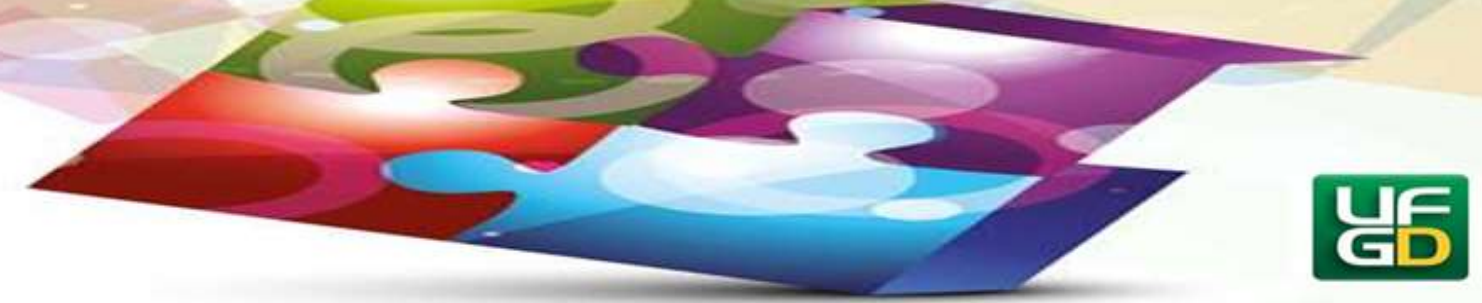

\title{
AUTONOMIA CURRICULAR DO PROFESSOR NOS SUBSISTEMAS DE ENSINO GERAL E TÉCNICO-PROFISSIONAL EM ANGOLA: UMA ANÁLISE CRÍTICA
}

\author{
TEACHER'S CURRICULAR AUTONOMY IN GENERAL AND TECHNICAL- \\ PROFESSIONAL EDUCATION SUBSYSTEMS IN ANGOLA: A CRITICAL ANALYSIS
}

António Luis JULIÃO ${ }^{1}$

Resumo: Esse artigo augura lançar um olhar crítico e reflexivo sobre as margens de autonomia curricular outorgadas aos professores por vias do Decreto Presidencial $n^{\circ} 276 / 19$, de 6 de Setembro e do Decreto Presidencial no 254/19, de 9 de Agosto, com o fim último de reforçar as suas possibilidades para melhorar a qualidade educativa. Para dar suporte ao mesmo, e inspirando-se na abordagem qualitativa, primou-se pelo levantamento do aparato teóricobibliográfico e documental, acerca da temática estudada neste trabalho. O texto desvela que, embora a Administração central confira algumas margens de autonomia retórica aos professores para flexibilizar e inovar o currículo em função do contexto educativo, sem o aperfeiçoamento transversal constante, a maturidade curricular e ausência da vontade e capacidade de autoregulação colectiva dos professores, tal autonomia será preterida em detrimento das receitas curriculares.

Palavras-chave: Autonomia curricular. Professor. Formação. Projectos. Sucesso escolar.

\begin{abstract}
This article aims to take a critical and reflective look at the margins of curricular autonomy granted to teachers through Presidential Decree $n^{\circ} 276 / 19$, of 6 September and Presidential Decree $\mathrm{n}^{\circ}$ 254/19, of 9 August, with the ultimate aim of enhancing their possibilities to improve educational quality. In order to support it, and taking inspiration from the qualitative approach, it was distinguished by the survey of the theoretical-bibliographic and documentary apparatus, about the theme studied in this work. The text reveals that, although the Central Administration confers some margins of rhetorical autonomy to teachers in order to make the curriculum more flexible and innovative according to the educational context, without constant transversal improvement, curricular maturity and the lack of collective will and capacity for self-regulation. teachers, such autonomy will be neglected at the expense of curriculum revenues.
\end{abstract}

Keywords: Curricular autonomy, Teacher, Training, Projects, School success.

\footnotetext{
${ }^{1}$ Especialização em Desenvolvimento Curricular e Inovação Educativa. Universidade Katyavala Bwila, Angola. E-mail: juliaoantonioluis23@gmail.com
} 


\section{MORIZONTES - REVISTA DE EDUCAÇÃO}

\section{Introdução}

Actualmente a autonomia da escola e dos professores é um tema que tem estado na pauta central dos debates educacionais em todo mundo. Falar de autonomia curricular pressupõe pensar numa complexa teia que engloba orientações teóricas e dinâmicas do contexto da prática educativa, tais como conhecimentos, competências, reflexões, capacidades e experiências vividas no âmbito da educação escolar e que concretizam o projecto global de formação dos alunos. Porém, a par desta orientação coexistem pressões políticas que colocam a tónica nos resultados, ignorando os processos que exigem uma maior emancipação por parte dos professores, no sentido de recriarem as lógicas burocráticas e legislativas, em função da hegemonia do contexto de operacionalização curricular.

Da mesma forma que democracia não se estabelece por decreto, mas por desejo e participação activa de uma sociedade, pensamos que a autonomia não pode ser determinada por lei. As leis podem ajudar no desenvolvimento da autonomia, criando condições para que tal se efective, mas, a verdadeira autonomia nas escolas requer vontade, responsabilidade e maturidade (MORGADO, 2000), de todos os segmentos envolvidos no processo.

A noção de autonomia das escolas deve ser analisada tendo em conta o panorama político e institucional dos sistemas escolares, sendo necessário considerar o papel do Estado como organizador e regulador do sector escolar e o professor como pedra angular, que faz o currículo acontecer. Daí a necessidade premente, associada, não só à transferência das competências de decisão do domínio do centro para o contexto das escolas e dos professores, como também a ousadia e destreza para a construção colectiva e consciente dessa mesma autonomia nos contextos de operacionalização curricular, ampliando as manobras de actuação do professor para o exercício pleno de sua principal actividade: fazer aprender.

Desta forma, à semelhança do que acontece em muitos outros países, em Angola, a legislação vigente (LBSEE 17/16, art. $\left.^{\circ} 4^{\circ}\right)^{2}$ consigna à educação um papel social e cultural de grande valor, esperando que a escola promova o desenvolvimento harmonioso das capacidades físicas, intelectuais, morais, cívicas, estéticas e laborais da jovem geração, de modo contínuo e

\footnotetext{
${ }^{2}$ Lei de Bases do Sistema de Educação e Ensino, que estabelece os princípios e as bases gerais do Sistema de Educação e Ensino da República de Angola, na África Austral.
} 


\section{MORIZONTES - REVISTA DE EDUCAÇÃO}

sistemático, elevando o seu nível científico, técnico e tecnológico, a fim de que os mesmos possam contribuir significativamente para o desenvolvimento socioeconómico, o bem-estar das populações e o progresso do País. Espera-se, ainda, à luz desse artigo, que a Educação contribua para a formação de indivíduos capazes de compreenderem os problemas nacionais, regionais e internacionais, de os abordarem de forma crítica e construtiva e que promova a sua participação activa na vida social, em sintonia com os demais elementos e princípios democráticos.

É exactamente neste contexto que se torna imprescindível a acção de professores conscientes, responsáveis e comprometidos com a profissão, dotados de liberdades, com capacidades inovadora, crítica, criativa e reflexiva, com experiências e com competências transversais e modernas, aspectos que, em conjunto permitirão que actuem como protagonistas no funcionamento eficiente e eficaz da escola, promovendo significativas aprendizagens para todos e fundamentalmente para cada um, visto que as escolas, os alunos e os contextos são diferentes. Esta diferença exige políticas e práticas locais de diferenciação positiva, exige na mesma proporção, ousadia e destrezas para conquista da própria autonomia, para criação de respostas justas e ajustadas com a actual realidade em que vivemos, pois nos tempos que pululam, ensinar tudo a todos como se fossem um só conduz necessariamente à desigualdade, ao insucesso e ao abandono escolar.

Inserida nesta lógica, embora em contradição com o articulado $105^{\circ}$, da LBSEE 17/16 de 7 de Outubro $^{3}$, a publicação do Decreto Presidencial n. ${ }^{\circ}$ 276/19, de 6 de Setembro ${ }^{4}$ e do

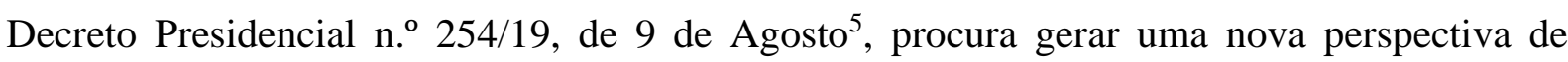
organização e gestão curricular outorgando algumas margens de autonomia significativa e determinante às escolas e aos professores, fundamentalmente no capítulo da concretização do projecto educativo, no desenvolvimento do projecto curricular, na inovação e sustentabilidade dos programas, fazendo jus ao princípio da realidade educativa. Contudo, e porque a autonomia é inversamente proporcional ao cumprimento escrupuloso das receitas curriculares do Centro, e directamente proporcional à maturidade e responsabilidade profissional dos seus agentes,

\footnotetext{
${ }^{3}$ Lei de Bases do Sistema de Educação e Ensino, que estabelece os princípios e as bases gerais do Sistema de Educação e Ensino da República de Angola.

${ }^{4}$ Regime Juridico do Subsistema de Ensino de Ensino Geral.

${ }^{5}$ Regime jurídico do Subsistema do Ensino Técnico-profissional.
} 


\section{MORIZONTES - REVISTA DE EDUCAÇÃO}

importa arvorar algumas inquietudes: será que os professores conhecem as margens de autonomia que lhes é outorgada pelos diplomas legais? Será que os professores têm sido capazes de procurar mecanismos que lhes conduza à autonomia sem excessiva dependência das prescrições curriculares? Será que no actual contexto socio-educativo e tendo em conta o professor real que o país possui, é mesmo viável outorgar substantivas margens de autonomia às escolas sem adendas? Até que ponto a autonomia curricular outorgada ou construída pode contribuir para a qualidade educativa sem a autonomia financeira das escolas? Como se posicionam os professores e gestores em relação ao próprio processo de autonomia das escolas?

Queremos ressaltar neste texto, que a autonomia curricular dos professores representa um importante valor, intrínseco à profissão, ao reforço da sua profissionalidade, dos seus direitos e, simultaneamente, um factor indispensável à democratização da escola e ao exercício de práticas pedagógicas comprometidas com a cidadania democrática e a autonomia dos alunos (LIMA, 1995), promovendo o sucesso educativo. Incompatível, por isso, com prescrições curriculares e tecnocráticas, que temos ainda verificado em nossa realidade educativa, que há muito clama por um ensino que responda aos imperativos hodiernos.

É nesta linha de pensamento que consideramos oportuno começar por reflectir sobre as margens de autonomia outorgadas aos professores por vias do Decreto Presidencial n. ${ }^{\circ}$ 276/19, de 6 de Setembro e do Decreto Presidencial n. ${ }^{\circ}$ 254/19, de 9 de Agosto, procurando confiar-lhes a contextualização, modelação e inovação do currículo proposto a nível nacional, no sentido de garantir um ensino que promova e garanta a qualidade educativa e o sucesso das aprendizagens. Para dar suporte ao mesmo e inspirando-se na abordagem qualitativa, primouse pelo levantamento do aparato bibliográfico e análise escalpelizada da legislação vigente.

Portanto, importa sublinhar, que a autonomia escolar parece ser ampla, mas sua realização plena e concreta, constitui ainda um desafio ingente, quer seja pela falta de (in)formação das pessoas que têm de exercê-la, das insuficiências infra-estruturais e tecnológicas, ou pela tradição centralista da Educação angolana. Afinal, autonomia não é uma palavra de fácil interpretação e sua subjectividade exige dos principais agentes educativos muita discussão e prática para lhe dar vida, perspectivando-a como um processo dinâmico de 


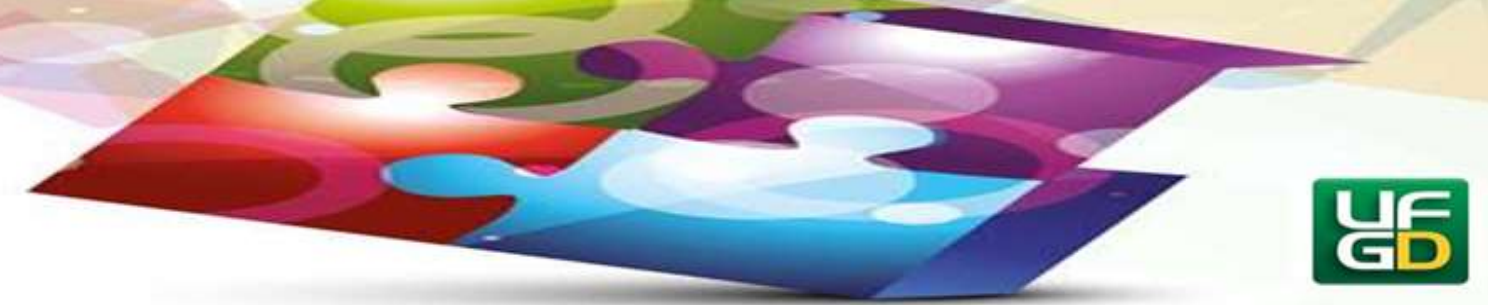

(re)construção consciente, colectiva e quotidiana, não vituperando as balizas das configurações da Administração Central.

\section{ESTADO DE ARTE}

\section{Um olhar compreensivo sobre o conceito de autonomia}

Autonomia é um termo e uma ideia que não é simples, nem de conceituá-la, nem de colocá-la em prática, fundamentalmente na realidade em análise. A palavra autonomia tem um significado plural, isto é, tem diferentes campos de aplicação. Segundo Freire (1998), autonomia é libertar o ser humano das cadeias do determinismo neoliberal. De acordo com Luck (2000), a autonomia é a capacidade de agir independentemente do sistema. Fernandes (1992) defende que significa descentralização, ou seja, caracteriza uma colectividade ou agrupamento territorial, que dispõe de poderes para definir os seus interesses, designar os seus órgãos e estabelecer a sua ordem social, sujeitos ao controlo da legalidade por parte do Estado, mas não à subordinação hierárquica.

Paraskeva; Morgado (1998) afirmam que esta pode ser compreendida, basicamente, como a capacidade que qualquer organismo/entidade, individual ou colectiva, detém de se poder reger por leis próprias, de actuar, de se orientar, de resolver os seus problemas, sem ter necessidade de recorrer a outrem, pressupondo, portanto, um determinado grau de independência, não vituperando nunca os postulados mais elementares da responsabilidade.

As opiniões dos autores supra aludidos não são excludentes entre si, mas confluentes. A autonomia, se por um lado significa liberdade, capacidade, poder, emancipação para fazer escolhas, actuar e/ou resolver problemas diversos, por outro lado exige uma dose de responsabilidade. A autonomia é fundamental para construção de uma sociedade democrática e para criar condições de participação política, onde as pessoas tenham vez e voz, digam o que desejam e que modelo de sociedade é melhor individual e colectivamente.

Nas escolas do contexto em análise, por via do artigo 105 , da LBSEE 17/16 de 7 de Outubro, tem subsistido a tradição de uma administração centralizada, decorrente de uma superprodução de normativos por parte do Estado para as escolas, procurando controlar e 


\section{MORIZONTES - REVISTA DE EDUCAÇÃO}

determinar muito do que aí se passa. No entanto, também sabemos que os normativos não anulam, por si só, a possibilidade de algumas dinâmicas internas imporem uma certa ordem anárquica ou, pelo menos, criarem alguns espaços de autonomia (SARMENTO, 1996). Estarão os professores preparados? Com que ferramentas?

A presença do termo autonomia no contexto educacional contemporâneo evidencia a sua tendência descentralizadora das actuais políticas educativas e curriculares, que idealizam a escola, não só como local estratégico de decisão curricular, mas também como espaço de mudanças organizacionais e funcionais que permitam melhorar o ensino e adequar o sistema educativo às exigências sociais, económicas e ambientais (MACHADO, 2006).

A autonomia da escola, dos professores e dos alunos, e de outros actores educativos, concretiza-se através de processos democráticos de tomada de decisões, incidindo sobre todas as áreas político-educativas (curriculares, didácticas, avaliativas, organizacionais, administrativas etc.), ainda que em graus variáveis. Consubstancia-se no exercício de uma pedagogia aberta, assegurando-lhe condições humanas, técnicas, tecnológicas e infraestruturais para a sua realização livre e democrática, traçando-lhe um quadro de valores, objectivos e projectos educativos de referência (LIMA, 2000). Por isso, parece-nos também fundamental reflectir sobre a necessidade de políticas educativas e curriculares descentralizadas como fundamento da autonomia da escola e dos professores e esteio para um ensino voltado para as aprendizagens de todos e fundamentalmente de cada um.

\section{Reflexão sobre a autonomia curricular da escola e do professor}

Segundo Morgado (2000), a autonomia do professor consiste na capacidade deste decidir de acordo com os princípios, valores e competências globais que orientam a construção da realidade escolar, no sentido de melhorar todo o processo de ensino-aprendizagem, não significando, por isso, liberdade total, pois se dela demandam capacidades de decisão, também fica claro as margens de responsabilidade e responsabilização. O mesmo autor advoga ainda ser um conjunto de processos e práticas utilizados nas escolas no sentido de seleccionar, organizar e contextualizar o currículo, na base do que pode ser face ao que deve ser. Uma das maneiras de proporcionar autonomia para as escolas é a descentralização, na qual a 


\section{MORIZONTES - REVISTA DE EDUCAÇÃO}

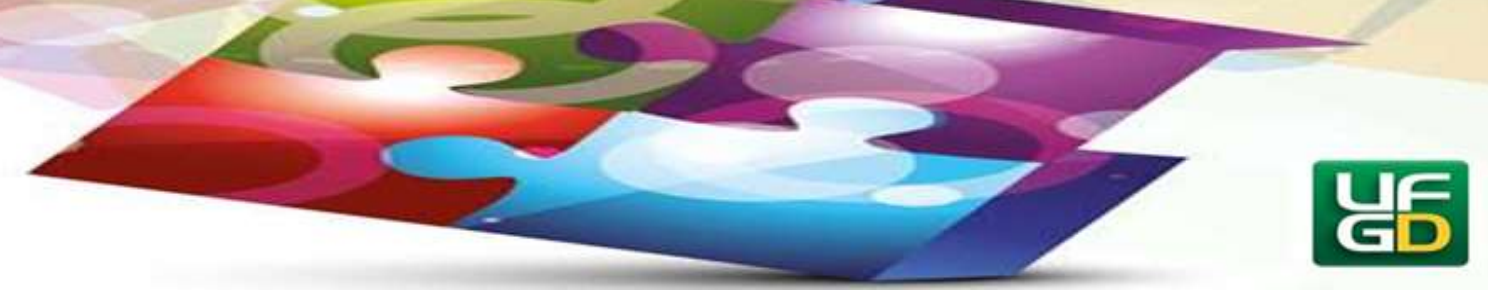

Administração Central estaria menos presente nas tomadas de decisões e resoluções de problemas quotidianos. A descentralização e autonomia só contribuiriam para tornar a escola mais plural e com o rosto da comunidade. A autonomia da escola, e particularmente a autonomia curricular, relativamente a um contexto específico, origina a territorialização das políticas educativas e curriculares, comprometendo de algum modo, alguns dos actores sociais e educativos, cujos papéis, até aí inócuos, passam a ser predominantes (PARASKEVA; MORGADO, 1998).

A autonomia curricular da escola concretiza-se na elaboração de um projecto educativo deliberativo, comprometendo todos os participantes na vida escolar e adaptando as características e os recursos da escola às pretensões da comunidade em que se insere (PARASKEVA; MORGADO, 1998). Contudo, apenas as organizações autónomas têm a capacidade de produzir projectos próprios, pois só elas têm a liberdade de escolher e decidir permitindo-lhe adequar o discurso oficial nacional aos contextos locais e aos recursos de que a escola dispõe para construir caminhos de maior qualidade (LEITE, 2003).

Numa perspectiva de análise diferente e complementar, Pacheco (2003 apud MACHADO, 2006) defende que a autonomia curricular, também denominada pedagógica, se intersecta com a autonomia administrativa e financeira e pode assumir formas diversas, decorrentes do tipo de políticas curriculares que se definem e implementam: (1) desconcentração - descentralização administrativa sem que se verifique a transferência de atribuições do centro para a periferia; (2) delegação ou descentralização funcional - possui margens de decisão mais importantes que a desconcentração; (3) devolução - contém uma relativa autonomia de governação; (4) privatização - o Estado deixa de possuir a tutela.

Em qualquer dos casos, a autonomia implica sempre a efectiva participação, responsabilidade, responsabilização e capacidade de decisão por parte dos distintos agentes educativos, nomeadamente ao nível da instituição escolar. No entender de Morgado (2000, p. 105), "existe uma relação directa entre a autonomia curricular exibida pelo professor e a responsabilidade que lhe é atribuída", com o intuito de se inverter a lógica top down de decisão curricular, característica de modelos mais centralizados, e que predomina no nosso contexto. Nesse sentido, procura evoluir-se de uma escola prescrita, conduzida e orientada pela 


\section{MORIZONTES - REVISTA DE EDUCAÇÃO}

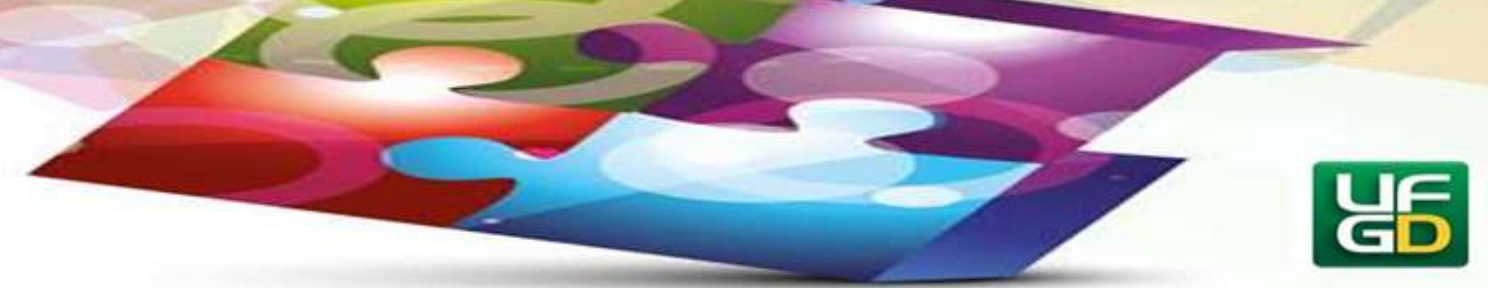

administração central, com fronteiras legais e físicas bem delineadas para uma escola viva, ligada umbilicalmente aos contextos de operacionalização curricular.

Outrossim, Morgado (2000) analisa o conceito de autonomia curricular atribuindolhe dois sentidos: (1) como conjunto de competências conferidas normativamente à escola, concedendo-lhe autoridade em matérias importantes, mas dependendo sempre da tutela e da própria administração, o que designa por autonomia decretada; (2) como um processo colectivo de construção que, respeitando os princípios e objectivos do sistema nacional de ensino, se adequa às especificidades locais por via de elaboração de projectos, o que designa por autonomia construída. Esses projectos são fundamentais, caso se pretenda responsabilizar e atribuir aos professores um papel construtivo, decisivo e activo no desenvolvimento do currículo (PACHECO, 2001), assumindo-se como verdadeiras pedras angulares na promoção e garantia das aprendizagem necessárias, por uma razão basilar: porque a missão central da escola é fazer aprender todos os alunos (ROLDÃO, p. 2009).

Nesta ordem de ideias, a autonomia curricular é considerada como uma mais-valia na mudança das práticas curriculares e na melhoria da qualidade das aprendizagens dos alunos (MORGADO, 2009). Com esta nova visão sobre a gestão curricular flexível e os seus incontestáveis e frondosos resultados, é provável que para o caso em concreto (tradição centralista) aconteça uma sucessiva transferência de competências de decisão para a escola e para os professores, sobretudo ao nível do trabalho que desenvolvem com os alunos, em conjunto com a comunidade em que a escola se insere. Todavia, estamos convencidos de que a transferência de quaisquer poderes do centro para a periferia (escolas), sem se acautelarem e estimularem as formações contínuas e espírito de partilha entre os professores, fundados no arejamento financeiro das instituições, não se lograrão os resultados inerentes aos processos de autonomia para tornar a escola a verdadeira trincheira firme do desenvolvimento social.

\section{A construção da autonomia curricular}

No que diz respeito à operacionalização curricular pelo professor, numa perspectiva autónoma, Morgado (2011) refere, pelo menos, quatro condições sem as quais se tornará difícil os docentes assumirem as responsabilidades que lhes são outorgadas, nomeadamente (1) Boa 


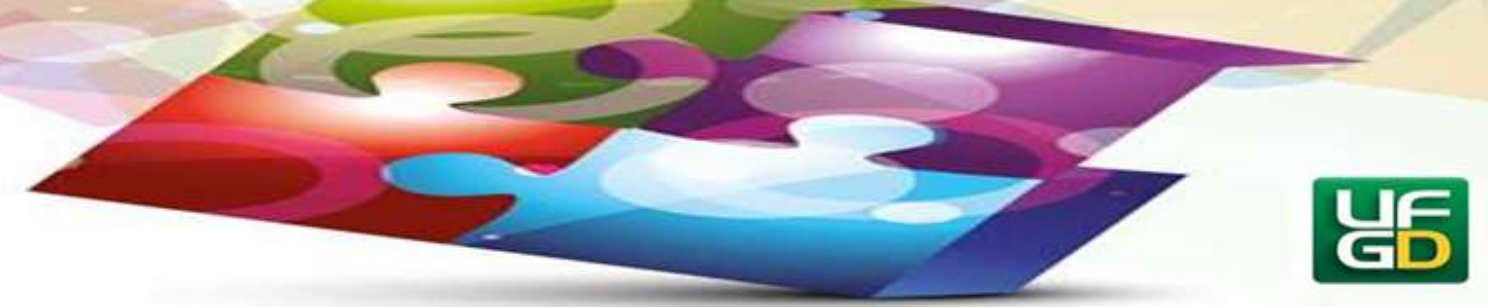

formação de base e uma permanente actualização pedagógica e científica que permitam tomar decisões fundamentadas e desenvolver inovações curriculares em função das mudanças que se pretendem implementar; (2) Possibilidade de aceder a recursos imprescindíveis à melhoria da qualidade de ensino; (3) Condições laborais que possibilitem a mudança dos ritmos e formas de trabalho; (4) Políticas educativas e curriculares que permitam que a escola se assuma como um verdadeiro espaço de decisão curricular, deixando de ser um mero local de implementação de decisões tomadas no seu exterior.

Se observarmos com alguma minúcia os requisitos para a construção da autonomia, podemos destacar que ela é directamente proporcional, tanto a uma boa e contínua formação dos professores, à existência de recursos financeiros para sustentar as iniciativas, quanto às políticas educativas e curriculares descentralizadas, que permitirão as escolas e os professores construírem seus projectos, melhorando seus desempenhos e ampliando o desenvolvimento das comunidades em que estão inseridas.

Para a realidade em análise ainda vislumbram-se longos caminhos a percorrer para se garantir uma autonomia eficiente e eficaz da esola, pois a qualidade da formação docente ainda é questionada, as iniciativas locais de capacitação permanente, quando existem são descontextualizadas, a insuficiência e/ou inexistência de uma base orçamental nas escolas e as políticas educativas e curriculares de lógica $U r b$ et $O_{r b i}{ }^{6}$. Tais questões se não forem urgentemente acauteladas em prol da bandeira da qualidade educativa que se pretende içar, importará relembrar as questões colocadas no prelúdio da nossa abordagem: Será que no actual contexto socioeducativo e tendo em conta o professor real que o país possui, é mesmo viável outorgar substantivas margens de autonomia às escolas? Como ser curricularmente autónomo no contexto angolano? Até que ponto a autonomia curricular outorgada ou construída pode contribuir para a qualidade educativa sem outras autonomias?

\footnotetext{
${ }^{6}$ Expressão latina, que significa "da cidade de Roma ao mundo", com a qual o Papa se dirige ao público em geral na praça de São Pedro, no momento da Páscoa e do Natal. No presente artigo, ao utilizarmos essa expressão, pretendemos destacar um currículo de tradição centralista ( art. $^{\circ} 105^{\circ}$, LBSEE 17/16), elaborado em Luanda, capital de Angola, mas que serve (a bem ou mal) para o resto do país, ignorando as especificidades e a hegemonia dos diferentes contextos.
} 


\section{MORIZONTES - REVISTA DE EDUCAÇÃO}

\section{A formação dos professores para autonomia curricular e transformação da escola}

Segundo Moreira (2014), e como temos vindo a acentuar, nos dias de hoje, por impulso das inúmeras crises, muitas escolas, em escala mundial, têm deixado de oferecer aos alunos as oportunidades essenciais para aprender face ao incerto futuro que os espera. Em situação tão difícil e complexa, há que se promover uma educação que garanta a apropriação de conhecimentos, habilidades e visões de mundo, que se mostrem indispensáveis para os alunos poderem se adaptar à aldeia contemporânea. Para isso, porém, há que se efectuar uma ruptura padigmática, pensando numa outra escola, capaz de se divorciar das práticas meramente executoras e costumeiras e, promover, de facto, estratégias inovadoras que permitam formar cidadãos à altura das dinâmicas globais/locais, isto é, capazes de enfrentar os grandes desafios próprios dos dias de hoje.

Tais desafios implicam que uma das principais preocupações dos professores do século XXI esteja fundada na formação e preparação contínua, que lhes forneçam destrezas imprescindíveis para construírem e gerirem suas autonomias curriculares e daí desenvolverem estratégias inovadoras, visando a motivação dos alunos, despertando-os para aprendizagens, que confiram sentido e utilidade social, isto é, aprendizagens significativas, que transforme a vida das comunidades. Dito de outro modo, clama-se por um sistema educativo descentralizado, um professor bem formado, adaptado aos novos tempos, que saiba gerir e construir suas margens de autonomia, propiciando a formação de indivíduos não conformistas, questionadores, autónomos, críticos, criativos com sede de busca e de humanidade. Neste sentido, a escola, embasada na perspectiva autónoma, fará toda diferença, tornando-se num verdadeiro território de reflexão, buscas, inovações, relações, diálogos, confrontos, desafios e práticas que anunciem novos tempos para novas exigências.

Na mesma dimensão, os alunos e os desafios hodiernos precisam que as politicas educativas e curriculares "desamarrem" a escola, no sentido de transformá-la, torná-la mais interessante, mais alegre, mais desafiante, moderna e inovadora. A esse respeito, Perrenoud (2002) defende a tese de que não pode haver mudança sem inovadores e inovadores sem formação qualificada. Pretende-se aqui destacar a ideia, segundo a qual, se a mudança é 


\section{MORIZONTES - REVISTA DE EDUCAÇÃO}

compatível com a autonomia do professor, este, com as competências transversais patrocinadas pela sua formação contínua, precisa actuar em rede de colaboração, no sentido de legitimar a sua autonomia e eficácia profissional, reduzindo a excessiva dependência das receitas curriculares do centro. Para que a escola seja, de facto, um espaço autónomo e desejável para os alunos e para a sociedade em geral, os professores são assim chamados a inaugurarem uma série de mudanças de atitudes, ideias, culturas e práticas pedagógicas, introduzindo novas formas de organizar e gerir o currículo, implementando novos projectos, criando materiais e recursos tecnológicos e novas formas de avaliar os alunos (SEBARROJA, 2001). Estamos a falar de práticas de inovação curricular, que visam mudar a forma de organizar o ensino e melhorar a forma das aprendizagens.

O teórico Fullan (1993, p. 14), nos lembra que "a mudança pessoal é o caminho para a mudança organizacional”. Esta ideia é reforçada por Alonso (1998) quando afirma que sem a acção decisiva do professor não há melhoria possível nos processos educativos. Assim, o papel dos professores bem preparados e com margens de autonomia significativas e determinantes para a melhoria das aprendizagens dos alunos e da escola é imprescindível para conseguir tornar a escola mais atractiva, e por consequência os processos de ensino-aprendizagem que aí decorrem, fazendo dela um espaço de decisão e inovação curricular. Portanto, fomentar a mudança nas escolas, e encontrar as respostas mais adequadas a cada contexto são aspectos que pressupõe a consideração e autonomia do professor como agente curricular por excelência, que ouse ultrapassar os limites do consumismo curricular e caminhe a passos largos e decisivos para a reinvenção de suas práticas curriculares, com a tónica dominante na qualidade das aprendizagens de todos os alunos.

Deste modo, e em função das mutações e incertezas globais, urgindo a necessidade de atribuir-se à escola e aos professores funções que se afastam do simples cumprimento do que é prescrito a nível nacional, deve-se proporcionar ferramentas gnoseológicas, financeiras, técnicas e tecnológicas para o processo de autonomia fazer seu eco na vida da escola. Assim, o currículo e os seus elementos mais substantivos serão seleccionados e organizados de forma a corresponder às situações reais, mobilizando-se os recursos locais, envolvendo-se as escolas e 


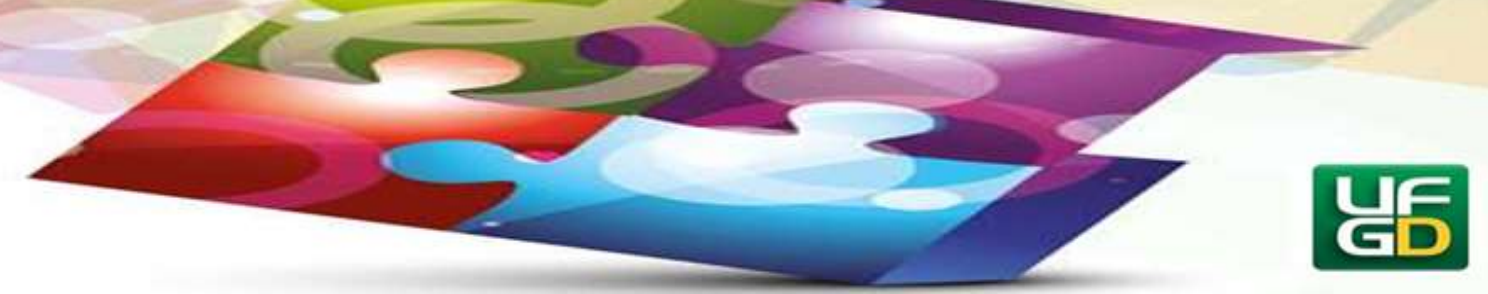

os seus agentes na procura de caminhos compagináveis a esses contextos reais, garantindo aprendizagens significativas para todos os alunos

\section{Análise reflexiva da autonomia nos documentos normativos}

Organização e Gestão Curricular: Subsistemas de Ensino Geral e Técnicoprofissional de Angola

Como temos vindo a destacar, a descentralização é vista não apenas como meio de democratização da sociedade, mas também de promover a melhoria da gestão de processos e recursos e, ainda, como condição de aliviar os organismos centrais, que estão sobrecarregados pelo gigantismo do sistema educativo, valorizando a acção da escola e dos professores. Importa ainda sublinhar, que a autonomia da escola não se altera profundamente com as mudanças normativas, mas depende sobretudo do processo pelo qual cada escola e os seus professores em função do contexto e de suas competências a vão construindo e, desse modo, apresentam um percurso orientado para diversificação e a flexibilização curriculares.

No contexto em análise, segundo o estudo do teórico Julião (2019), embora legalmente estejam conferidas algumas margens de autonomia aos professores em Angola, várias observações quotidianas e alguns relatos indiciam a existência de um profundo desconhecimento dessa prerrogativa legal, pois, em inúmeros casos, os docentes limitam-se a cumprir o que lhes é central e curricularmente prescrito, em detrimento de tomadas de decisões partilhadas, colocando em causa a qualidade do processo de ensino e aprendizagem perseguida no país. Por que razão os professores “preferem” actuar à margem das autonomias legalmente outorgadas? Será que não possuem as competências necessárias para assegurar essa autonomia e melhorar a aprendizagem dos alunos? para o nosso contexto em particular, estarão mesmo os professores em condições de usufruir da autonomia curricular e produzir resultados? Que competências e condições lhes foram passadas para o efeito?

A tentativa de descentralização do Ministério da Educação, embora de forma tímida e tácita, procura gerar uma nova perspectiva de organização e gestão curricular outorgando algumas margens de autonomia significativas e determinantes às escolas e aos professores, 


\section{MORIZONTES - REVISTA DE EDUCAÇÃO}

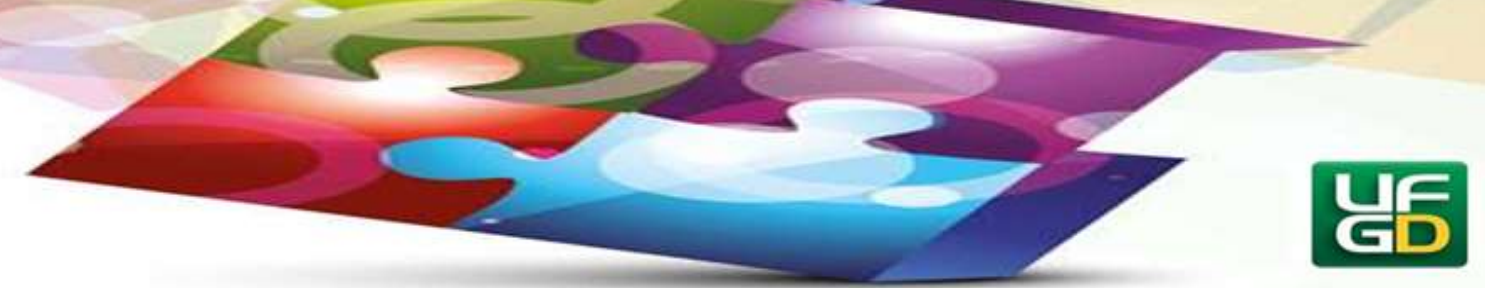

fundamentalmente no capítulo da flexibilização dos programas, concretização do projecto educativo, no desenvolvimento do projecto curricular, na inovação e sustentabilidade dos programas, fazendo jus ao princípio da realidade educativa. Tal facto podemos vislumbrar nos normativos - Decreto Presidencial $n^{\circ}$ 160/18, de 3 de Julho (ANGOLA, 2018); Decreto Presidencial $n^{\circ}$ 276/19, de 6 de Setembro (ANGOLA, 2019) e o Decreto Presidencial $n^{\circ}$ 254/19, de 9 de Agosto (ANGOLA, 2019), embora a LBSEE 17/16, de 7 de Outubro (ANGOLA, 2016) não faça eco sobre essa matéria, chegando até a coarctar a liberdade dos agentes de educação, colocando a tónica na centralidade e obrigatoriedade no cumprimento escrupuloso das receitas curriculares. Portanto, do ponto de vista geral, parece-nos existir uma certa abertura para a promoção de alguma margem de autonomia por parte dos professores, embora defendamos a necessidade premente de que a autonomia seja directamente proporcional ao aprimoramento das competências dos professores e da existência prévia das condições técnicas, tecnológicas e infra-estruturais para puder atingir o objectivo da sua essência e existência, condições que pensamos que a nossa realidade ainda faz um viés.

\section{Estrutura e Organização do Subsistema do Ensino Geral em Angola}

O subsistema de Ensino Geral estrutura-se em Ensino Primário e Ensino Secundário (art. $8^{\circ}$, do Decreto Presidencial n. ${ }^{\circ}$ 276/19, de 6 de Setembro). O Ensino Primário, fundamento do Ensino Geral e condição indispensável para a frequência do Ensino Secundário, é organizado em três ciclos de aprendizagens, compreendendo duas classes para cada ciclo e organiza-se da seguinte forma: i) $-1^{\mathrm{a}}$ e $2^{\mathrm{a}}$ Classes; ii) $-3^{\mathrm{a}}$ e $4^{\mathrm{a}}$ Classes; iii) $-5^{\mathrm{a}}$ e $6^{\mathrm{a}}$ Classes (art. $10^{\circ}$ ). O Ensino Secundário Geral é o nível que sucede o Ensino Primário e prepara os alunos para o ingresso no Ensino Superior ou no mercado de trabalho imediatamente, após formação profissional complementar $\left(\operatorname{art} .13^{\circ}\right)$. O mesmo compreende três classes cada e organiza-se da seguinte forma: i) - O I Ciclo do Ensino Secundário Geral, compreende a 7. ${ }^{\mathrm{a}}, 8 .^{\mathrm{a}}$ e $9 .^{\mathrm{a}}$ Classes. ii) - O II Ciclo do Ensino Secundário Geral compreende a $10 .^{\mathrm{a}}, 11 .^{\mathrm{a}}$ e $12 .{ }^{\mathrm{a}}$ Classes (art. $14^{\circ}$ ).

\section{Estrutura e Organização do Ensino Técnico-profissional em Angola}

O Subsistema do Ensino Técnico-profissional (nível de ensino secundário) é o fundamento do Sistema de Educação e Ensino que assegura a preparação técnica, tecnológica 


\section{MORIZONTES - REVISTA DE EDUCAÇÃO}

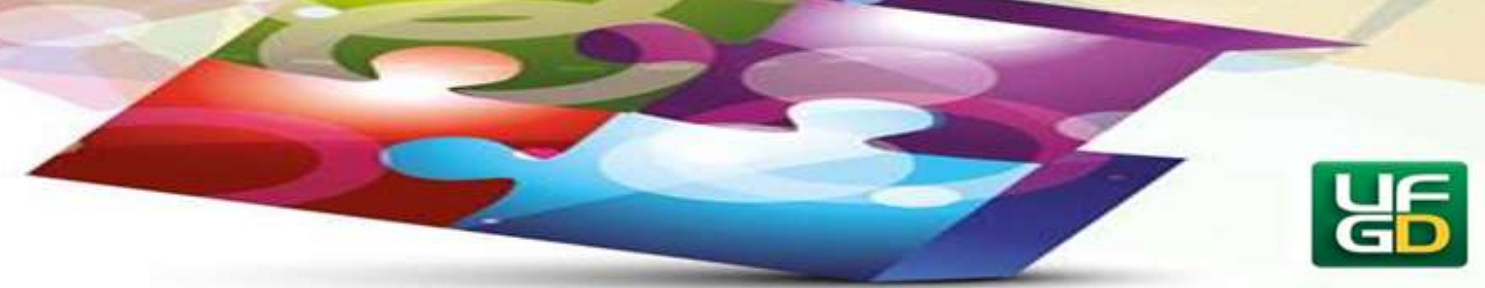

e profissional dos indivíduos, necessária para a conclusão de cada um dos seus ciclos, para a sua inserção no mercado de trabalho, sem prejuízo da possibilidade da continuação de estudos no Subsistema de Ensino Superior. O subsistema estrutura-se em formação profissional Básica e Ensino Secundário Técnico-profissional (artigo $7^{\circ}$, do Decreto Presidencial n. ${ }^{\circ}$ 254/19 e artigo $36^{\circ}$, da LBSEE n 17/16, de 7 de Outubro). A formação profissional Básica compreende o I Ciclo ( $7^{\mathrm{a}}, 8^{\mathrm{a}}$ e $9^{\mathrm{a}}$ Classes) (artigo $\left.9^{\circ}\right)$. O ensino Técnico-profissional realiza-se após a conclusão da $9^{\mathrm{a}}$ Classe, com duração de 4 anos e compreende 4 classes $\left(10^{\mathrm{a}}, 11^{\mathrm{a}} ; 12^{\mathrm{a}}\right.$ e $\left.13^{\mathrm{a}}\right)$ nos Institutos Técnicos e Politécnicos (artigo 13º).

\section{Que margens de autonomia são outorgadas aos professores nos dois Subsistemas?}

Nos normativos, que regulam o Subsistema de Ensino Geral e de Ensino técnicoprofissional, é visível a lógica, que visa contribuir para inverter a tradição de uma gestão excessivamente centralizada, transferindo-se poderes significativos de decisão do plano central para os planos regional e local, reanimando o papel dos professores, enquanto agentes curriculares por excelência. Será que tais margens de autonomia são acompanhadas de competências e capacidades para a sua gestão? Temos vindo a sublinhar que se torna conveniente passar de um currículo pesadamente centralizado para um currículo com rosto da escola, que brota dos consensos e conflitos dos principais agentes das próprias instituições. Entretanto, não ignoramos os pressupostos basilares para se acautelar os desafios dessa descentralização. Esta passagem é um grande desafio para as políticas educativas e curriculares, para a acção organizacional das escolas, para a acção profissional dos professores, e para a comunidade educativa em geral.

Segundo os articulados $25^{\circ 7}$ e $28^{\circ 8}$, dos dois Subsistemas de Ensino aqui em análise, em particular nas alíneas $a$ e $f$, através dos quais a organização curricular deve ter em consideração o seguinte:

A autonomia na concretização do projecto educativo e no desenvolvimento do projecto curricular, adequado ao contexto educativo.

\footnotetext{
${ }^{7}$ Organização Curricular, do Subsistema de Ensino Técnico-Profissional (Decreto Presidencial no 254/19, de 9 de Agosto).

${ }^{8}$ Organização Curricular, do Subsistema de Ensino Geral (Decreto Presidencial no 276/19, de 6 de Setembro).
} 


\section{MORIZONTES - REVISTA DE EDUCAÇÃO}

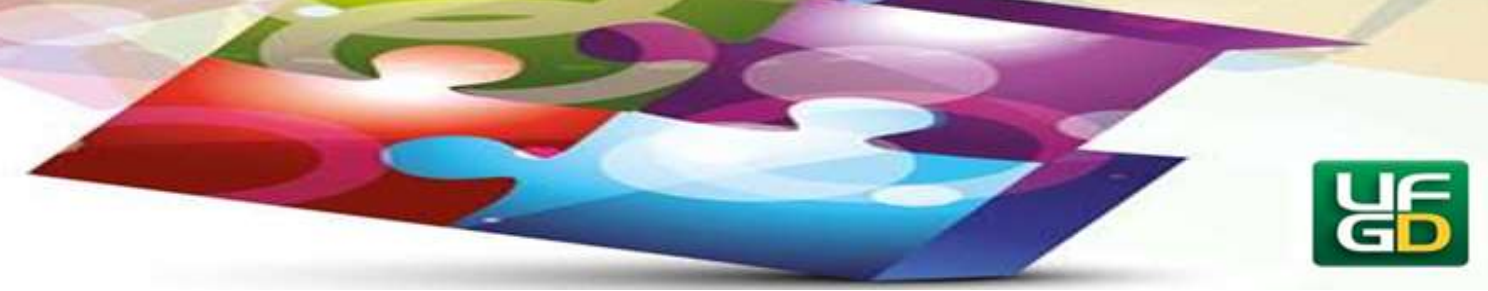

O Sistema de Educação e Ensino no contexto angolano viveu muito fechado para si mesmo, fruto do seu contexto histórico e ideológico, mas hoje e em função das novas dinâmicas locais e globais, embora de forma tímida, vai outorgando algumas margens de liberdades consideráveis aos professores (MORGADO, 2000), mormente no capítulo da construção do projecto educativo e do desenvolvimento do projecto curricular adequado ao contexto, o que de alguma forma poderá contribuir para o êxito e sucesso educativo. Nesta ordem de ideias os projectos podem constituir um instrumento basilar de concretização da autonomia e da qualidade educativa, desde que sejam concebidos e desenvolvidos com a participação e a partilha de responsabilidades dos vários actores educativos. Desta forma, para o nosso contexto importa questionar se os agentes de educação reúnem as condições necessárias para tais desafios. Será que em Angola se reconhece a centralidade da escola nos contextos de decisão curricular ou as margens de autonomia funcionam como um tópico discursivo e meramente retórico? A existência de projectos - educativo, curricular não conduz necessariamente à autonomia, a não ser que se fale de uma autonomia controlada, de uma autonomia relativa e de uma autonomia de negação (PACHECO, 2003, apud MACHADO, 2006).

\section{Flexibilidade, dinamismo, inovação e sustentabilidade dos programas de ensino.}

Um outro ponto de destaque prende-se com a flexibilização e inovação dos programas curriculares, uma vez que constituem um factor central de um projecto educacional de matriz democrática, remetendo a escola à adequação do estilo de ensino aos estilos e ritmos de aprendizagem, criando condições para que todos aprendam e maximizem as suas oportunidades de sucesso escolar. Esta perspectiva de flexibilização e diferenciação curricular (SOUSA, 2010) é assegurada essencialmente a nível das escolas e das salas de aula, exigindo, porém, novos processos de organização do ensino que invertam o circuito da uniformidade curricular, adaptando as práticas e processos às características de todos e de cada aluno. Pretende-se, assim, romper com o modelo que faz do professor um mero executor e mediador técnico do currículo prescrito para um verdadeiro pensador/agente curricular. Parece-nos que esta é uma condição imprescindível para melhorar a aprendizagem dos alunos e, consequentemente, promover o seu sucesso educativo. 


\section{MORIZONTES - REVISTA DE EDUCAÇÃO}

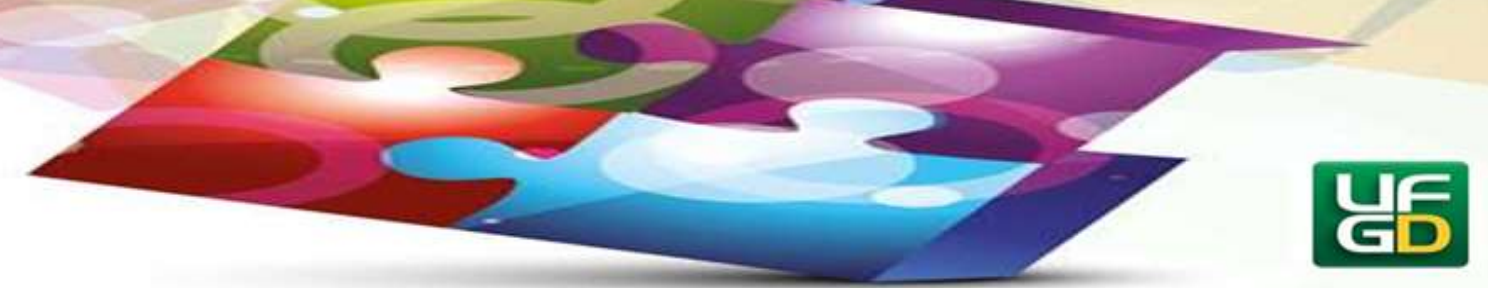

Como vemos, algumas margens de autonomia consideráveis são outorgadas às escolas e aos professores para promoção do sucesso escolar, assumindo novas posturas face ao actual contexto. Contudo, a realidade educativa ainda demonstra algumas práticas curriculares, que fazem um viés aos postulados da legislação, provavelmente por desconhecimento da norma, por alguma resistência ou por indigência de algumas competências para puder materializar os aportes dos documentos normativos nas suas realidades escolares. Por conseguinte, pelo facto de muitos documentos serem concebidos monoliticamente pelas estruturas centrais, sem se ouvir as subjectividades das pessoas (APPLE, 1999) muitos professores preferem instalar-se nas suas zonas de conforto, privilegiando funções executoras, baseadas em práticas descontextualizadas e inflexíveis, pondo em causa o alcance dos objectivos programáticos e cumulativamente a referida qualidade de ensino. Leite (2003) conclui que essa tendência centralista na implementação do currículo desincentiva os professores e não é sustentável. Assim, a autonomia curricular deve ser resultado de um processo de aperfeiçoamento contínuo de trabalho, formação, reflexão, comprometimento e, se possível, de envolvimento de toda comunidade educativa, tendo em vista a eficácia da instituição escolar e o sucesso educativo.

Em síntese, a mensagem que queremos destacar é que a centralidade da autonomia curricular para que os professores adaptem o currículo proposto a nível nacional às características e necessidades dos alunos e do contexto da escola, pode constituir um caminho pedagógico facilitador e instigador de aprendizagens mais significativas para os alunos e, por isso, susceptíveis de promoverem o seu sucesso educativo.

\section{Da autonomia que temos à autonomia que precisamos em Angola}

Após a uma análise circunstanciada sobre autonomia curricular dos professores em Angola por via dos documentos normativos, fundamentalmente nos Subsistemas de Ensino Geral e Técnico-profissional, torna-se imperioso extrairmos algumas notas distintivas para protagonizarmos outras reflexões.

Do ponto de vista geral, nas escolas do contexto em análise tem subsistido a tradição de uma administração centralizada, decorrente de uma superprodução de normativos por parte do Estado, procurando controlar e determinar muito do que aí se passa, colocando em causa, 


\section{MORIZONTES - REVISTA DE EDUCAÇÃO}

tanto a riqueza da diversidade dos contextos, quanto o próprio sucesso educativo, embora reconheçamos que a nova atitude da administração central a que se refere os citados diplomas cristaliza a intenção de transferir para as escolas algumas margens de decisão e competências que, durante um longo período de tempo, foram do seu foro de decisão. Todavia, de que forma estão as escolas e fundamentalmente os professores preparados e organizados para esse novo desafio curricular?

A legislação vigente em Angola (LBSEE 17/16, art. $^{\circ} 4^{\circ}$ ) consigna à educação um papel social e cultural de grande valor, esperando que a escola promova o desenvolvimento harmonioso das capacidades físicas, intelectuais, morais, cívicas, estéticas e laborais da jovem geração do País. Para concretizar tais intentos, a administração central outorga algumas margens de autonomia às escolas, que se materializa fundamentalmente na flexibilização e inovação dos programas e na elaboração de um projecto educativo e curricular. Nesta óptica, corroboramos com Machado (2006), quando alude que um dos instrumentos que mais contribui para uma efectiva(re)contextualização do currículo e, por consequência, uma verdadeira mudança da escola é a construção, realização e avaliação de projectos, uma vez que são vistos como uma forma de envolver os vários actores educativos nos processos de trabalho e nas tomadas de decisão que configuram os destinos educacionais de cada comunidade. Nesta ordem de ideias os projectos podem constituir um instrumento basilar de concretização da autonomia, desde que sejam concebidos e desenvolvidos com a participação e a partilha de responsabilidades dos vários actores educativos.

O projecto educativo de escola formalizará as intenções e as acções da política educativa e curricular de uma escola ou agrupamento de escolas. Nele se explicitam os princípios, os valores, as metas e as estratégias segundo as quais a escola se propõe cumprir a sua função educativa. Considerado como um instrumento de concretização e de gestão da autonomia da escola, o projecto educativo deve ter como ponto de partida a discussão e análise dos vários problemas e aspirações da escola e procurar envolver os diferentes agentes educativos. Só depois se deve passar à acção, uma vez que o projecto educativo deve prever a operacionalização de um conjunto de estratégias que procurem concretizar os intentos delineados (MACHADO, 2006). 


\section{MORIZONTES - REVISTA DE EDUCAÇÃO}

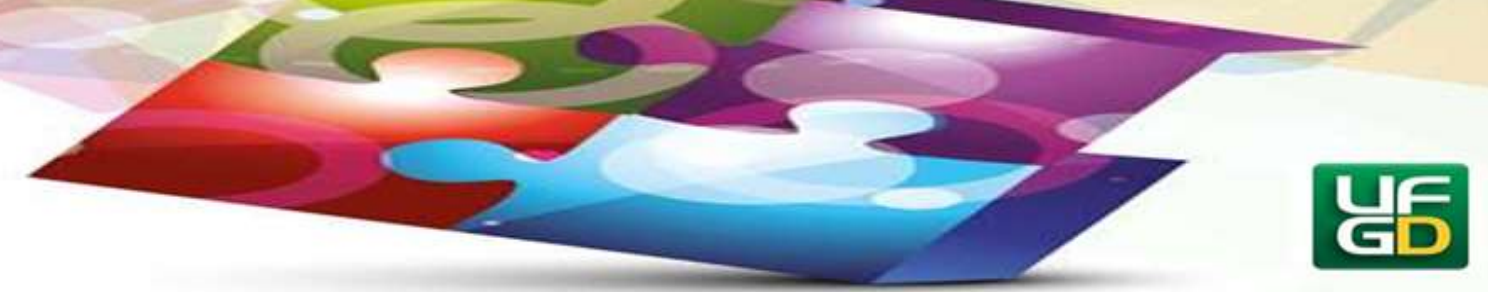

Por seu turno, o projecto curricular de escola define, em função do currículo nacional e do projecto educativo de escola, as prioridades curriculares da escola, as competências essenciais e transversais em torno das quais se organizará o projecto e os conteúdos que serão trabalhados em cada área curricular. As estratégias de concretização e desenvolvimento do currículo nacional e do projecto curricular de escola, visando adequá-los ao contexto de cada turma, são objecto de um projecto curricular de turma (MACHADO, 2006).

Contrariamente às vozes discordantes, que veiculam a inexistência absoluta de autonomia das escolas e dos professores em Angola, os normativos estudados demonstram que as margens de autonomia assentam fundamentalmente na possibilidade de se flexibilizar e inovar os programas, da construção de projectos educativos e desenvolvimento do projecto curricular, cabendo questionar sobre os modos que tais autonomias têm sido gerenciadas e se têm ajudado a melhorar e transformar o fenómeno educativo.

A escola, enquanto centro das políticas educativas e curriculares, deve aprender a construir a sua autonomia a partir da comunidade em que se insere, dos seus problemas e potencialidades, contando com uma nova atitude da administração central, regional e local, que possibilite uma melhor resposta aos desafios da mudança, contrariando a lógica da uniformização curricular, que não reconhece o carácter dinâmico e diversificado dos contextos educativos (FLORES; FLORES, 2000, p. 85).

Face ao actual modelo de autonomia outorgada e não/pouco usufruída que temos, e fruto dos desafios, incertezas e complexidades que perpassam a escola, obviamente, se quisermos ter um lugar no futuro, precisamos urgentemente avançar para duas reflexões cruciais que se entrecruzam: a primeira, as politicas educativas e curriculares devem constituirse como verdadeiramente descentralizadas, libertando as escolas das "amarras" normativas/burocráticas e criando condições técnicas, tecnológicas, orçamentais e humanas para a verdadeira emancipação das mesmas, proporcionando desta maneira um modelo organizativo e curricular flexível compaginável aos desafios dos diferentes contextos. Este modelo de escola que precisamos em função da multiplicidade dos contextos e dos imperativos globais fará deslocar o centro do ensino para a aprendizagem e, ao lado de um modelo baseado no ensino por disciplinas, promoverá o trabalho interdisciplinar baseado em projectos e focado 


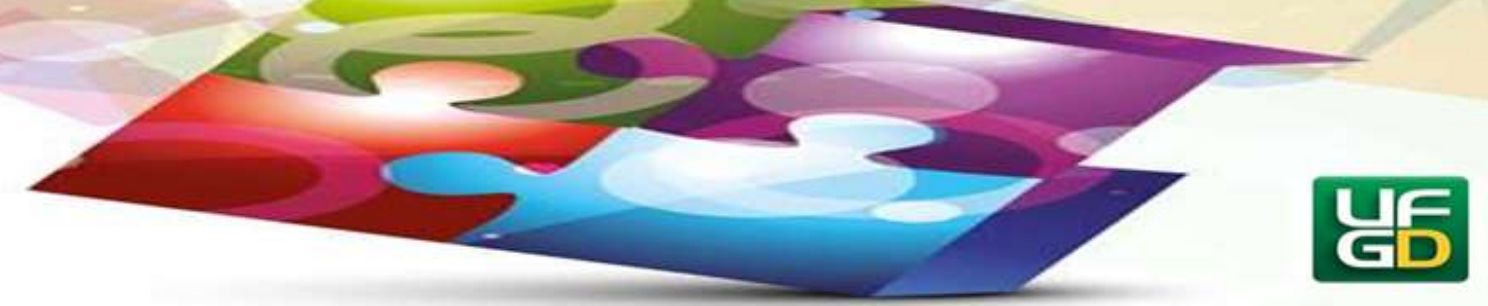

na construção do conhecimento, onde os alunos colocados perante aos desafios e problemas complexos poderão investigar e propor soluções reais, que gerem impacto nas suas comunidades. Desta forma, a escola terá sentido e significado na vida dos seus envolventes, pois passará de mera reprodutora à inovadora, crítica e transformadora com poder de atrair a comunidade. Pretende-se, assim, romper com o modelo que faz do professor, mesmo com algumas margens de autonomia não usufruída, um mero executor e mediador técnico do currículo prescrito, tornando-se numa verdadeira pedra angular e curricular.

A segunda, assenta fundamentalmente na consciência dos professores, que assumindo o espírito patriótico e de profissionais de ensino devem pautar por uma conduta responsável, colaborativa, de reflexões, de partilha e de boas práticas por via dos grupos de aprendizagem, inaugurando outras práticas de ensino, no sentido de construírem suas próprias autonomias e contribuírem para o sucesso educativo dos alunos e da comunidade em geral. Se tal não se efectivar, quaisquer margens de autonomia que se desejar outorgar mais aos professores poderá contribuir para o insucesso educativo dos alunos, visto que em nossa perspectiva a autonomia curricular é inversamente proporcional ao grau de incompetência.

Portanto, sabemos que a autonomia da escola não se exerce profundamente com as alterações legislativas, mas depende sobretudo do processo pelo qual cada escola e os seus professores a vão construindo e, desse modo, apresentam um percurso orientado para a adequação, diversificação e a flexibilização. A autonomia é/devia ser mais um processo de construção colectiva (ainda que responsavelmente clandestina) do que o artefacto legislativo que o determina e requer mais autoria que acção em conformidade, assim como pressupõe a opção por um padrão de trabalho que requer a cooperação dos pares e destes com outros profissionais no quadro de lógicas de trabalho em rede interdisciplinar e de respeito pela individualidade de cada um. 


\section{MORIZONTES - REVISTA DE EDUCAÇÃO}

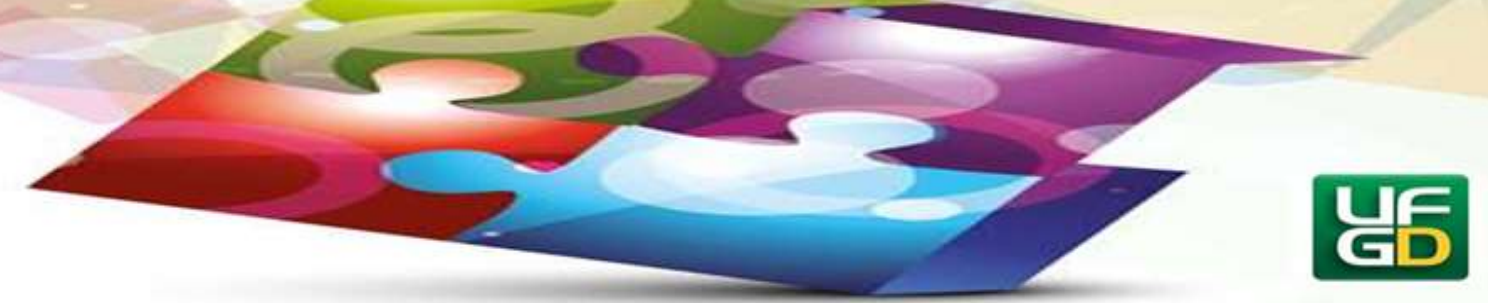

\section{Considerações Finais}

Em jeito de balanço final, importa referir que muitos são os desafios e inúmeras são as possibilidades que se colocam diante das escolas e dos professores para actuarem rumo à promoção do sucesso escolar. Ficou patente que o currículo prescrito não reconhece o carácter dinâmico e diversificado dos contextos educativos e coarcta a capacidade dos professores e das escolas conceberem os seus próprios projectos formativos em função das características contextuais e dos aprendentes. Neste sentido, a Administração Central, por via dos regimes jurídicos dos Subsistemas de Ensino Geral e Técnico-profissional, tenta libertar as escolas outorgando significativas margens de autonomia, quer por via da orientação para a flexibilização e inovação dos programas, quer por via da elaboração de um projecto educativo e curricular para a emancipação das mesmas. Assim, o currículo e os seus elementos mais substantivos serão seleccionados e organizados de forma a corresponder às situações reais, mobilizando-se os recursos locais, envolvendo-se as escolas e os seus agentes na procura de caminhos compagináveis ao sucesso educativo.

Entretanto, a realidade educativa do país ainda demonstra muitas práticas e processos escolares que atentam contra esses postulados normativos, provavelmente por desconhecimento da norma, por alguma resistência ou por indigência de algumas competências para puder materializar os aportes dos documentos normativos. Como temos vindo sucessivamente a defender, num contexto onde a qualidade da formação docente ainda é questionada, as iniciativas locais de capacitação permanente descontextualizadas, infra-estruturas pouco recomendáveis, a insipiência e/ou inexistência de recursos materiais e tecnológicos e a falta de uma base orçamental nas escolas, quaisquer margens de autonomia, que se desejar outorgar poderá não lograr os êxitos que se desejam, pois mais ou menos autonomia exige e exigirá sempre uma significativa maturidade curricular dos agentes.

Ademais, queremos destacar que a autonomia da escola não acontece com as alterações normativas, mas depende sobretudo do processo pelo qual cada escola e os seus professores a vão construindo e, desse modo, apresentam um percurso orientado para a diversificação, flexibilização e inovação. A autonomia é mais um processo de construção 


\section{MORIZONTES - REVISTA DE EDUCAÇÃO}

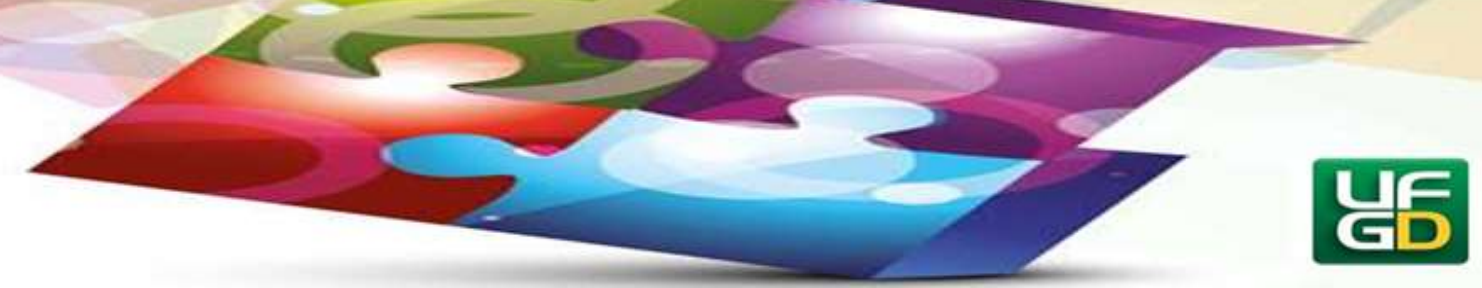

colectiva do que um artefacto legislativo que pressupõe a opção por um padrão de trabalho que requer a cooperação dos pares e destes com outros profissionais no quadro de lógicas de trabalho em rede e de respeito pela individualidade de cada um.

Assim, a escola, enquanto centro das políticas educativas e curriculares, tem, assim, de construir a sua própria autonomia a partir da comunidade em que se insere, dos seus problemas e potencialidades reais, contando com uma nova atitude da administração central e local, que possibilite uma melhor resposta face aos desafios do contexto e da comunidade em geral. Os professores, enquanto pedras angulares e peças cruciais do currículo, numa lógica colegial e diferente das incúrias curriculares são convocados e desafiados a reflectirem crítica, constante e localmente sobre suas práticas curriculares, aperfeiçoando o seu fazer pedagógico e fazendo diariamente opções que proclamam a promoção do sucesso escolar e da qualidade educativa para todos e fundamentalmente para cada uma das almas que faz a escola acontecer.

\section{REFERÊNCIAS}

APPLE, Michael. Conhecimento oficial: a educação democrática numa era conservadora. Petrópolis, RJ: Vozes, 1999.

ANGOLA. DECRETO-Lei n. ${ }^{\circ}$ 17/16, de 7 de Outubro - publicado no Boletim Oficial de Angola. I Série - n. ${ }^{\circ} 170$ - Cria os principios e as bases gerais do Sistema de Educação e Ensino, 2016. Disponível em: <https://lexlink.eu/conteudo/geral/ia-serie/3784573/leino1716/14793/por-tema>. Acesso em: Dez/2019.

ANGOLA. DECRETO Presidencial n. ${ }^{\circ}$ 160/18, de 3 de Julho - publicado no Boletim Oficial de Angola. I Série - n. 95 - Aprova o Estatuto dos Agentes de Educação, 2018. Disponível em: $<$ https://www.lexlink.eu/conteudo/geral/educacao-e-ensino/3864345/decreto-presidencial-no16018/26794/por-tema>. Acesso em: Jan/2020.

ANGOLA. DECRETO Presidencial n. ${ }^{\circ}$ 254/19, de 9 de Agosto - publicado no Boletim Oficial de Angola. I Série - n. ${ }^{\circ} 102$ - Aprova o Regime Juridico do Subsistema de Ensino Técnicoprofissional, 2019. Disponível em: <https://angolaforex.com/2019/08/14/diario-da-republica-ia-serie-n-o-102-de-9-agosto-de-2019/amp/>. Acesso em: Jan/2020.

ANGOLA. DECRETO Presidencial n. ${ }^{\circ}$ 276/19, de 6 de Setembro - publicado no Boletim Oficial de Angola. I Série - n. ${ }^{\circ} 116$ - Aprova o Regime Juridico do Subsistema de Ensino de 


\section{MORIZONTES - REVISTA DE EDUCAÇÃO}

Ensino Geral, 2019. Disponível em: <https://www.lexlink.eu/conteudo/geral/educacao-eensino/3908111/decreto-presidencial-no-27619/26818/por-tema>. Acesso em: Jan/2020.

ALONSO, Maria. Inovação Curricular, Formação de Professores e melhoria da escola: uma abordagem reflexiva e reconstrutiva sobre a prática da inovação/formação (Tese de Doutoramento). Universidade do Minho, Braga, 1998. Disponível em: $<$ http://repositorium.sdum.uminho.pt/handle/1822/10840>. Acesso em: nov/2019.

FERNANDES, António. A centralização burocrática do ensino secundário. Tese (Doutorado em Disciplina) - Universidade do Minho, Braga, Portugal, 1992.

FLORES, Maria; FLORES, Manuel. Do Currículo Uniforme à Flexibilização Curricular: algumas reflexões. In José Augusto Pacheco, José Carlos Morgado e Isabel Carvalho Viana (orgs.), Políticas Curriculares: Caminhos de Flexibilização e Integração. Actas do IV Colóquio sobre Questões Curriculares. Braga: IEP/Universidade do Minho, pp.83-92, 2000.

FREIRE, Paulo. Pedagogia da autonomia: saberes necessários à prática educativa. 7. ed. Rio de Janeiro, RJ: Paz e Terra, 1998.

FULLAN, Michael. Change forces. Probing the depths of educational reform. Londres: Falmer Press, 1993.

JULIÃO, António. A Autonomia Curricular do Professor em Angola: Limites, Desafios e Possibilidades. Revista Praxis Pedagógica, Brasil, v. 2, nº 1, pp. 1-14, jan/mar, 2019. Disponível em: <http://dx.doi.org/10.20500/rce.v14i29.22155>. Acesso em: Jan/2020.

LIMA, Licínio. Organização escolar e democracia radical: Paulo Freire e a governação democrática da escola pública. São Paulo, SP: Cortez, 2000. (Guia da escola cidadã, v. 4).

LIMA, Licínio. Reformar a administração escolar: a recentralização por controlo remoto e a autonomia como delegação política. Revista Portuguesa de Educação, v. 8, n. 1, p. 57- 71, 1995. Disponível em: 〈https://scholar.google.com/scholar?cluster=2128923412105254243hl=en\&oi=scholar> Acesso em: Dez/2019

LEITE, Carlinda. Para uma escola curricularmente inteligente. Porto: Asa, 2003.

LÜCK, Heloísa. Perspectivas da Gestão Escolar e Implicações quanto à Formação de seus Gestores. Em Aberto, Brasília, v.17, n.72, p. 11-33, fev./jun.2000. Disponível em: $<$ http://rbep.inep.gov.br/ojs3/index.php/emaberto/article/view/2634>. Acesso em: Jan/2020. 


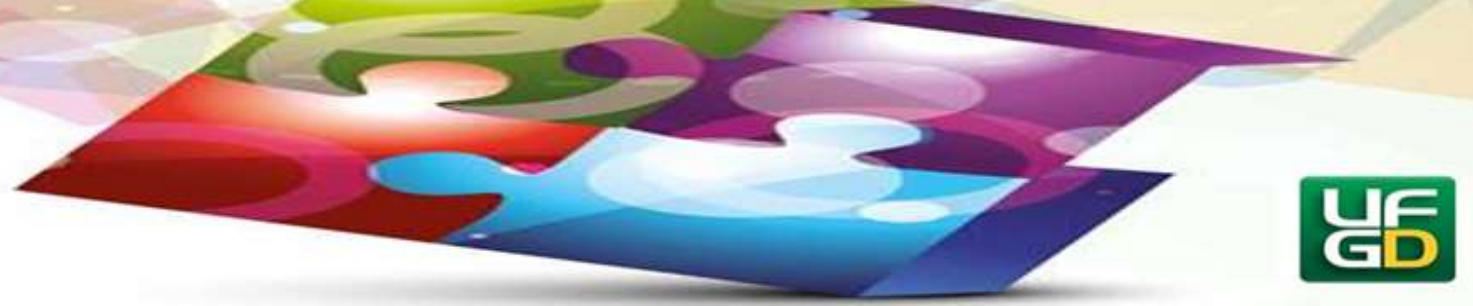

MORGADO, José. Projeto curricular e autonomia da escola: das intenções às práticas. Revista Brasileira de Política e Administração da Educação, Goiânia, v. 27, n. 3, p. 391-408, set.-dez. 2011. Disponível em: <https://seer.ufrgs.br/rbpae/article/view/26411>. Acesso em: out/2019.

MORGADO, José. Avaliação e autonomia curricular: dos discursos emancipadores à (des)regulação das práticas. In: CONGRESSO INTERNACIONAL GALEGO-PORTUGUÊS DE PSICOPEDAGOGIA, 10., 2009, Braga. Actas... Braga: Universidade do Minho, p. 3590602, 2009.

MORGADO, José. A (des) construção da autonomia curricular. Lisboa: Asa, 2000.

MACHADO, Neves. O papel do professor na construção do currículo. Dissertação (Mestrado em Ciências da Educação) - Instituto de Educação e Psicologia da Universidade do Minho, Braga, 2006. Disponível em: <http://repositorium.sdum.uminho.pt/handle/1822/6156>. Acesso em: Jan/2020.

MOREIRA, Flávio. Renovando a escola e o currículo. In J. C. Morgado e A.D. Quitembo (Orgs). Currículo, Avaliação e Inovação em Angola: Perspectivas e Desafios. Benguela, Angola: Ondjiris Editores, 2014.

PACHECO, José. Tendências de descentralização das políticas curriculares. In: PACHECO, J. (Org.). Políticas educativas: o neoliberalismo em educação. Porto: Porto, 2001.

PARASKEVA, Menelau; MORGADO, José. Autonomia Curricular: uma nova ferramenta ideológica. In José Augusto Pacheco, João Menelau Paraskeva; Ana Maria Silva (orgs.), Reflexão e Inovação Curricular. Actas do III Colóquio sobre Questões Curriculares. Braga: IEP/Universidade do Minho, pp.107-126, 1998.

ROLDÃO, Céu. Estratégias de Ensino: o saber e o agir do professor. Porto: Fundação Manuel Leão, 2009.

SARMENTO, Jacinto. A Escola e as Autonomias. Cadernos Pedagógicos, n. ${ }^{\circ}$ 9. Porto: Edições Asa, 1996.

SEBARROJA, Carbonell. A aventura de Inovar: A mudança na escola. Porto: Porto Editora, 2001.

SOUSA, Francisco. Diferenciação curricular e deliberação docente. Porto: Porto, 2010. 